Quadling, C. \& Stocker, B. A. D. (1957). J. gen. Microbiol. 17, 424-436

\title{
The Occurrence of Rare Motile Bacteria in some Non-motile Salmonella Strains
}

\author{
By C. QUADLING* and B. A. D. STOCKER \\ The Guinness-Lister Unit, Lister Institute of Preventive Medicine, \\ Chelsea Bridge Road, London, S.W. 1
}

SUMMARY: The presence of rare motile bacteria in 22 of 48 non-motile Salmonella strains tested has been inferred from the production of satellite micro-colonies in semi-solid medium. Such rare motile bacteria have been isolated by micromanipulation; they are not motile mutants, since their progeny are nearly all non-motile. They transmitted motility to only a few of their descendants, as if their motility were due to the presence of non-multiplying motility-conferring particles which were transmitted to their progeny at cell division. It is inferred that small numbers of such particles arise during an intracellular 'event'; this event probably consists of a transient ability to synthesize new flagella. The frequency of events in one Salmonella $O$ strain was found to be $c .4 \times 10^{-5} /$ bacterium/generation.

In many bacterial genera both motile and non-motile strains are found; for instance in Salmonella (see Stocker, Zinder \& Lederberg, 1953). Strains in which a small minority of cells are motile have been reported, e.g. Jordan, Caldwell \& Reiter (1934); such strains are usually termed 'poorly motile'. The possible significance of 'poor motility' as an indication of cellular variation has received little attention. Stocker et al. (1953), in the course of experiments on the transduction of motility, grew Salmonella strains on a semi-solid medium; motile strains gave spreading growth, whereas completely non-motile strains grew only at the site of inoculation. They noted, however, that in some 'non-motile' strains the growth at the site of inoculation was surrounded by satellite micro-colonies, which on subculture yielded only non-motile growth indistinguishable from the original strain; antiflagellar serum prevented the formation of the satellite colonies. Stocker et al. suggested that in the strains concerned a very small fraction of the cells were motile and migrated through the agar, but produced non-motile progeny, constituting the satellite microcolonies.

In subsequent experiments on the abortive transduction of motility Stocker (1956b) and Lederberg (1956), by micromanipulation, isolated motile bacteria from suspensions of non-motile Salmonella strains which had been treated with phage lysates of motile strains (i.e. lysates capable of transducing motility); in these experiments they encountered a class of motile cells which transmitted motility down only one line of descent to a single one of their progeny of each generation. Stocker $(\mathbf{1 9 5 6} b)$ supposed that this unilinear transmission of motility (discussed by Stocker, 1956a) resulted from the transmission of a hypothetical non-replicated cell structure, the motility-conferring (MC)

* Present address: Bacteriology Division, Science Service, Canada Department of Agriculture, Ottawa. 
particle, which was perhaps a flagellum (or its basal granule) or a cell wall bearing one or more flagella. Stocker $(1956 b)$ concluded that in abortive transduction of motility, the synthesis of motility-conferring particles by a small minority of the bacteria resulted from the presence in each such bacterium of a transduced gene (which also was transmitted unilinearly).

The synthesis of motility-conferring particles by a small proportion of bacteria in a culture, resulting from causes other than transduction, is inferred from the observations described in the present paper. The spontaneous production of satellite colonies has been investigated in a considerable number of non-motile strains of Salmonella and other genera, and the spontaneous occurrence of rare motile bacteria in some satellite-producing non-motile Salmonella strains has been directly demonstrated. Such bacteria have been isolated by micromanipulation and shown to produce mainly non-motile progeny with only a few motile descendants, each of which transmits motility unilinearly. It is suggested that these motile bacteria, which are demonstrably not true motile mutants, result from 'events' consisting of the transient ability of a cell to synthesize particulate locomotor apparatus (MC particles). A method of measuring the frequency of such events per bacterium per generation has been devised.

\section{METHODS}

Organisms. Strains used in this work are listed by Quadling (1956a). Non-motile Salmonella strains were principally obtained by courtesy of Prof. J. Lederberg, Department of Genetics, University of Wisconsin, Wis., U.S.A., and of Dr Joan Taylor, at the Salmonella Reference Laboratory of the Public Health Laboratory Service, Colindale, London, N.W. 9. Many of these strains are listed by Stocker et al. (1953). Vibrio cholerae $\mathrm{O}$ strains were obtained from Dr K. Bhaskaran at the Wright-Fleming Institute of Microbiology, St Mary's Hospital Medical School, London, W. 2. Proteus O strains were obtained from the National Collection of Type Cultures. Escherichia coli $\mathbf{O}$ strains of serotypes 0111 and 055 were provided by $\mathrm{Dr}$ Joan Taylor.

Media. Nutrient broths were made from a tryptic digest of lean beef or from a papain digest of horse meat (Asheshov, 1941) and nutrient agar by addition of $2 \%(\mathrm{w} / \mathrm{v})$ Japanese agar. Semi-solid or 'motility' medium was that of Edwards \& Bruner (1942) as used by Stocker et al. (1953). It contains $0 \cdot 4 \%(\mathrm{w} / \mathrm{v})$ 'Difco' agar and $8.0 \%(\mathrm{w} / \mathrm{v})$ 'Difco' gelatine in a peptone broth basal medium. In some experiments only $4 \%$ gelatine was used and in others gelatine was omitted altogether. Such omissions are mentioned in the description of experiments.

Stock cultures. Cultures were maintained on Dorset's Egg slopes, which were generally kept at laboratory temperature. In some cases stock cultures were started from a single bacterium isolated by micromanipulation. Such singlecell cultures were stored at $4^{\circ}$; they are designated by the appropriate strain number, followed by an oblique stroke and a capital letter, e.g. SL 191/G indicates a culture derived from a single bacterium, picked by micromanipulation, from a culture of strain SL191. 
Cultures used in experiments. All cultures were grown at $37^{\circ}$, unless otherwise stated. A streak from the stock culture was plated-out, so as to give discrete colonies after overnight incubation; a colony was then subcultured into nutrient broth. All experiments were carried out with bacteria which were in the logarithmic phase of growth. Cultures were grown unshaken in loosely capped tubes, or $20 \mathrm{ml}$. McCartney bottles. Viable counts were made by the method of Miles \& Misra (1938), or by spreading samples of $0.1-0.5 \mathrm{ml}$. of suitable dilutions over the surface of nutrient agar plates.

Motility. Broth cultures were examined for motility by low-power darkground microscopy, as described by Stocker (1956b). The motility characteristics of cultures were also inferred from the colony patterns produced during growth on semi-solid medium (Pl. 1, figs. 1, 2).

Micromanipulation. The methods used were those of de Fonbrune (1949) as described by Stocker (1956b).

\section{RESULTS}

\section{Behaviour of non-motile strains grown in semi-solid medium}

A pour-plate technique was used to test non-motile strains for the production of satellite micro-colonies. Cultures in logarithmic growth in broth at $37^{\circ}$ are suitably diluted. Melted semi-solid medium $(0 \cdot 3 \%(\mathrm{w} / \mathrm{v})$ agar, no gelatine) at $44^{\circ}$ is then inoculated with the diluted culture so as to give about 2 bacteria $/ \mathrm{ml}$. of medium. This inoculated medium is at once poured into $10 \mathrm{~cm}$. Petri dishes and incubated at $37^{\circ}$. After 16-18 hr. incubation, colonies derived from the individual organisms of the inoculum can be distinguished. Positive results are indicated by the presence of satellite micro-colonies associated with the larger parent colonies. All colonies are well defined and most of the satellites are clearly separated from the parent colonies (Pl. 1, fig. 3).

Forty-eight non-motile Salmonella strains (of species other than $S$. gallinarum and $S$. pullorum) were tested in this way and satellites found with 22 of them. Eight of the strains tested were flagellated and non-motile ('paralysed') strains. Three of the paralysed strains produced satellites. These results are summarized in Table 1, which also records results of tests with some non-motile strains of genera other than Salmonella.

Table 1. Results of tests of non-motile strains in semi-solid medium. Production of satellite micro-colonies indicates the presence of rare motile bacteria

\begin{tabular}{lccc} 
& \multicolumn{2}{c}{$\begin{array}{c}\text { Satellite } \\
\text { micro-colonies }\end{array}$} \\
\cline { 2 - 3 } Non-motile strains & present & absent & Total \\
strains* & 19 & 21 & 40 \\
lagellated but non-motile strains* & 3 & 5 & 8 \\
coli O strains & 3 & 4 & 7 \\
rains & 1 & 2 & 3 \\
ae O strains & 5 & 0 & 5 \\
& 31 & 32 & 63
\end{tabular}

Salmonella O strains*

Salmonella flagellated but non-motile strains*

Escherichia coli $\mathrm{O}$ strains

Proteus $O$ strains

Vibrio cholerae $\mathbf{O}$ strains

Totals

* Salmonella strains of species other than $S$. gallinarum and S. pullorum. 
The numbers of satellites produced during overnight incubation at $37^{\circ}$ varied from strain to strain. In some strains an average of only one or a few satellites were present per colony; in others there were many satellites round each colony. Within a given strain the frequency of satellite production remained approximately constant from experiment to experiment, except that appearances varied with different batches of medium; in general the stiffer the medium the fewer the satellites. The medium used here contained no gelatine in order to make the tests as sensitive as possible.

The production of satellites by some non-motile Proteus, Vibrio and Escherichia strains shows that this phenomenon is not confined to a single group of organisms. Satellite formation was also looked for in species and genera characterized by non-motility: no positive results were obtained in tests of about forty Shigella strains or of about thirty Salmonella gallinarum and $S$. pullorum strains.

\section{Estimation of satellite frequency}

Quantitative data on satellite frequency were obtained by an elaboration of the technique described above. Estimates were made of the rate at which satellites (and by inference, motile individuals) were produced during growth of a non-motile Salmonella typhimurium O strain SW 545 (Stocker et al. 1953). In the experiments reported here a streptomycin-resistant mutant (SL 191/G) of this strain was used.

Melted semi-solid medium $(0.4 \%, \mathrm{w} / \mathrm{v}$, agar, $4 \%, \mathrm{w} / \mathrm{v}$, gelatine) was inoculated with a culture of SL 191/G which had previously been in logarithmic growth at $37^{\circ}$. It was arranged that about 2-5 bacteria were present in each ml. of semi-solid medium. The inoculated medium was at once poured into pre-warmed $10 \mathrm{~cm}$. Petri dishes in $20 \mathrm{ml}$. amounts which were immediately incubated at $37^{\circ}$. It was assumed that each viable bacterium would grow and divide to form a colony; motile bacteria arising during growth of these colonies would swim out into the medium and initiate satellite micro-colonies.

After $5 \mathrm{hr}$. at $37^{\circ}$ the plates were chilled, to set the medium, and were then left at bench temperature $\left(c .20^{\circ}\right)$. Because the medium contained gelatine it was solid at bench temperature; no further bacterial movement could occur. However, growth continued at this temperature until both parent and satellite colonies were visible. After some $18 \mathrm{hr}$. at $20^{\circ}$ the plates were examined under a magnification of $c$. $\times 10$ and the proportion of parent colonies with and without satellites was determined.

The average number of colonies/plate was calculated from viable counts made on the inoculum. The number of bacteria/plate after $5 \mathrm{hr}$. at $37^{\circ}$, i.e. at the time of chilling, was determined from a replicate plate which itself was not chilled. The entire contents of this plate were suspended, by means of a magnetic stirrer, in a known volume of broth and a viable count made. The ratio of inoculum number to final bacterial number gives a value for the average number of bacteria per colony at the conclusion of incubation at $37^{\circ}$.

We believe that satellite micro-colonies arise as a result of intra-bacterial 'events' whose nature will be discussed later. The frequency of such satellite- 
producing events/bacterium/generation may be calculated from the data on the following assumptions: (1) that the probability per bacterium of suffering an event does not vary from one colony to another or at different times during the growth of a colony, and (2) that there is no great variation in population size between colonies in a single plate. The data to be described support the first assumption; counts of viable bacteria in colonies picked individually, under the microscope, showed that the second assumption was reasonable. On these assumptions the proportion of colonies with no satellites $\left(\boldsymbol{P}_{\mathbf{0}}\right)$ can be put equal to $e^{-z}$, the first term of the Poisson summation. In this expression $z$ is the average number of events per colony. From the average number of events calculated in this way, and the average number of bacteria per colony, the event frequency per bacterium per generation can be calculated by the use of a suitable formula, e.g. formula (1) of Newcombe (1948).

The results of two experiments of this type are summarized in Tables 2 and 3. An event frequency of $c .4 \times 10^{-5}$ per bacterium per generation was

Table 2. Determination of event frequency per bacterium per generation by pourplate method: strain $S L 191 / G$ incubated for $5 \mathrm{hr}$. at $37^{\circ}$ in semi-solid medium; colonies examined for satellites after further growth at $20^{\circ}$

\begin{tabular}{|c|c|c|c|c|c|c|}
\hline \multirow{2}{*}{$\begin{array}{l}\text { Expt. } \\
\text { no. }\end{array}$} & \multicolumn{2}{|c|}{$\begin{array}{l}\text { Colonies examined } \\
\text { for satellites }\end{array}$} & \multirow{2}{*}{$\begin{array}{c}\text { Proportion } \\
\text { negative } \\
\left(P_{0}\right)\end{array}$} & \multirow{2}{*}{$\begin{array}{l}\text { Calculated } \\
\text { mean } \\
\text { number of } \\
\text { events } \\
\text { per colony* }\end{array}$} & \multirow{2}{*}{$\begin{array}{c}\text { Calculated } \\
\text { mean number } \\
\text { organisms } \\
\text { per colony } \dagger\end{array}$} & \multirow{2}{*}{$\begin{array}{c}\text { Calculated } \\
\text { event } \\
\text { frequency }\end{array}$} \\
\hline & Negative & & & & & \\
\hline I & $\begin{array}{l}164 \\
100\end{array}$ & $\begin{array}{l}465 \\
263\end{array}$ & $\begin{array}{l}\mathbf{0 . 3 5 3} \\
\mathbf{0} \cdot \mathbf{3 8}\end{array}$ & $\begin{array}{l}1.04 \\
0.97\end{array}$ & $\begin{array}{l}1.33 \times 10^{4} \\
3.07 \times 10^{4}\end{array}$ & $\begin{array}{l}5.5 \times 10^{-5} \\
2 \cdot 2 \times 10^{-5}\end{array}$ \\
\hline
\end{tabular}

* Calculated from the first term of the Poisson series, $P_{0}=e^{-z}$, where $z$ is the mean number of events per colony.

+ Calculated from viable counts at beginning and end of incubation at $37^{\circ}$.

$\ddagger$ Per bacterium per generation.

Table 3. Distribution of numbers of satellites per colony in Expt. 1 of Table 2

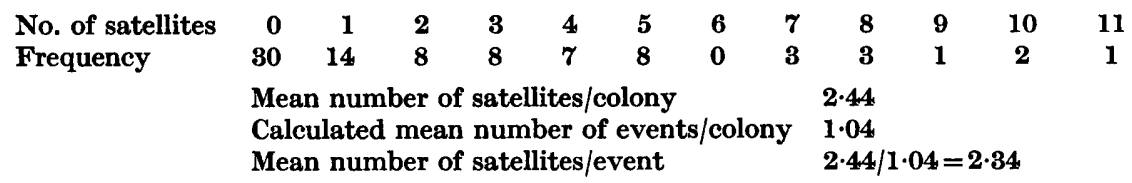

found for SL191/G. The observed average number of satellites per colony exceeded, by a factor of between two and three, the average number of events per colony calculated from the Poisson distribution. If the hypothesis of satellite-producing events occurring at random is correct this means that an event results in the appearance of an average of several satellites.

Estimates of event frequency were also made at different times during the growth of the parent colonies by withdrawing replicate plates from incubation at intervals between 4 and $6 \mathrm{hr}$. (Table 4). As would be expected if events occur with a constant probability per bacterium per generation, the mean 
number of satellites per colony and the calculated mean number of events per colony increased with increasing duration of incubation at $37^{\circ}$, i.e. with increasing number of viable organisms per colony: but there was little divergence between estimates of numbers of satellites per event made at different times. This indicates that the assumed Poissonian distribution of numbers of events per colony is probably justified. If, as it now appears, several satellites result from one event, then the distribution of numbers of satellites per colony will not be Poissonian. It is evident from the data of Table 3 that the distribution of numbers of satellites per colony is nonPoissonian.

Table 4. Numbers of satellites per colony, in pour-plates, after various times of incubation at $37^{\circ}$

Pour-plates of strain SL 191/G were withdrawn from incubation at $37^{\circ}$ at stated times, chilled, and examined for satellites after further growth at $20^{\circ}$.

\begin{tabular}{|c|c|c|c|c|c|}
\hline $\begin{array}{c}\text { Time at } 37^{\circ} \\
\text { (hr.) }\end{array}$ & $\begin{array}{c}\text { Colonies } \\
\text { examined }\end{array}$ & $\begin{array}{c}\text { Proportion } \\
\text { negative }\end{array}$ & $\begin{array}{c}\text { Calculated } \\
\text { mean number } \\
\text { of events/ } \\
\text { colony }\end{array}$ & $\begin{array}{l}\text { Average } \\
\text { number } \\
\text { satellites/ } \\
\text { colony }\end{array}$ & $\begin{array}{l}\text { Mean number } \\
\text { satellites/ } \\
\text { event }\end{array}$ \\
\hline 4 & 181 & 0.72 & 0.33 & $0 \cdot 78$ & $2 \cdot 35$ \\
\hline $4 \frac{1}{2}$ & 148 & $0 \cdot 66$ & 0.42 & 0.91 & $2 \cdot 15$ \\
\hline 5 & 143 & 0.42 & 0.87 & 1.8 & $2 \cdot 07$ \\
\hline $5 \frac{1}{2}$ & 152 & 0.28 & $1 \cdot 26$ & $2 \cdot 87$ & $2 \cdot 27$ \\
\hline 6 & 151 & $0 \cdot 1$ & $2 \cdot 31$ & $5 \cdot 89$ & 2.55 \\
\hline
\end{tabular}

The estimates of event frequency are minimum estimates and no high degree of precision can be claimed for them. Their accuracy depends largely on the efficiency of detection of motile bacteria by the pour-plate method. As mentioned above, the stiffer the medium the fewer the satellites found; small variations in stiffness occur from experiment to experiment and even from plate to plate within a single experiment. It is possible that a class of motile bacteria unable to swim in this medium remained undetected. Furthermore it is likely $a$ priori that there will be some delay between the event and the initiation of the first resulting satellite, for a bacterium in which an event occurs will not become motile until it has grown functional flagella. Consequently those events which have only just occurred at the time of chilling the plates will not be detected and the calculated event-frequency will be an underestimate. However, similar values for event frequency were obtained in similar experiments carried out on different occasions.

\section{Isolation of motile bacteria by micromanipulation}

Stocker et al. (1953) suggested that a small fraction of the bacteria might be motile in $\mathbf{O}$ strains which produced satellites during growth on semi-solid medium. This suggestion was verified by experiments in which growing, standing-drop, cultures of SL 191/G were observed by low-power dark-ground microscopy. Each drop was $c .10^{-3} \mathrm{ml}$; ; evaporation was minimized and contamination avoided by the use of a thin protective film of mineral oil. As expected, motile bacteria were present in very small numbers; they were 
rarely detectable before about $10^{6}$ bacteria were present in a drop, when on average about ten motile bacteria were seen.

Subculture of satellite micro-colonies yielded non-motile growth with the characteristics of the parent $O$ strain, which suggested that motility of the satellite-initiating bacteria was transitory. It was therefore of interest to isolate such motile bacteria by micromanipulation and to observe their behaviour.

Large populations of strain SL 191/G, in exponential growth, were examined in hanging drop, using the oil-chamber technique described by Stocker $(\mathbf{1 9 5 6} b)$. Rare motile bacteria were seen and a number were transferred, each to a separate micro-drop of sterile broth. The isolated motile bacteria were allowed to grow and divide at $c .20^{\circ}$, and the resulting populations were examined when between 200 and 300 bacteria were present in each drop.

The progeny of these motile bacteria were, for the most part, non-motile. However, in most populations a few motile bacteria were found amongst the non-motile majority (Table 5). Had the original motile bacteria been motile mutants one would have expected them to give rise to motile populations. The results obtained suggested that the original motile bacteria were able to transmit motility to few, if any, of their progeny.

Table 5. Populations derived from individual motile bacteria, isolated from a culture of strain $S L 191 / G$ by micromanipulation, examined after about eight generations growth at $20^{\circ}$

$\begin{array}{lc}\text { Description of population } & \begin{array}{c}\text { Frequency } \\ \text { (populations) }\end{array} \\ \text { All bacteria non-motile } & 17 \\ \text { 1 motile bacterium, rest non-motile } & 27 \\ \text { 2 motile bacteria, rest non-motile } & 6 \\ \text { 3 motile bacteria, rest non-motile } & 2 \\ 4 \text { motile bacteria, rest non-motile } & 1 \\ \text { Total no. of populations } & 53\end{array}$

A similar situation was encountered by Stocker (1956b) and by Lederberg (1956) during investigations on the transduction of motility to non-motile Salmonella strains. To account for his results, Stocker put forward the hypothesis of unilinear transmission of motility resulting from the unilinear transmission of motility-conferring (MC) particles, referred to in the introduction to this paper. On this hypothesis a bacterium with only one MC particle will give rise to a clone containing only one motile descendant. Repeated isolation of the motile bacterium, at intervals during growth of the clone, would constitute a critical test of the hypothesis: if the hypothesis is correct the re-isolated motile bacterium should always produce one motile descendant and its non-motile progeny should produce only non-motile descendants. An experiment of this sort will be described next.

A motile bacterium was isolated from a culture of SL 191/G and grown in a micro-drop of broth. This micro-culture and the others arising from it in the course of the experiment were inspected at intervals. Whenever a motile bacterium was observed it was removed to a fresh drop of broth. The course of 
this experiment is summarized in Fig. 1. During its first four divisions the isolated motile bacterium gave rise to two motile and a number of non-motile progeny and at no time during the experiment were more than two motile bacteria found amongst the descendants of the original motile isolate. The transmission of motility was followed for respectively $c$. eleven and $c$. sixteen generations in each of the two lines; thereafter no motile descendants were seen.

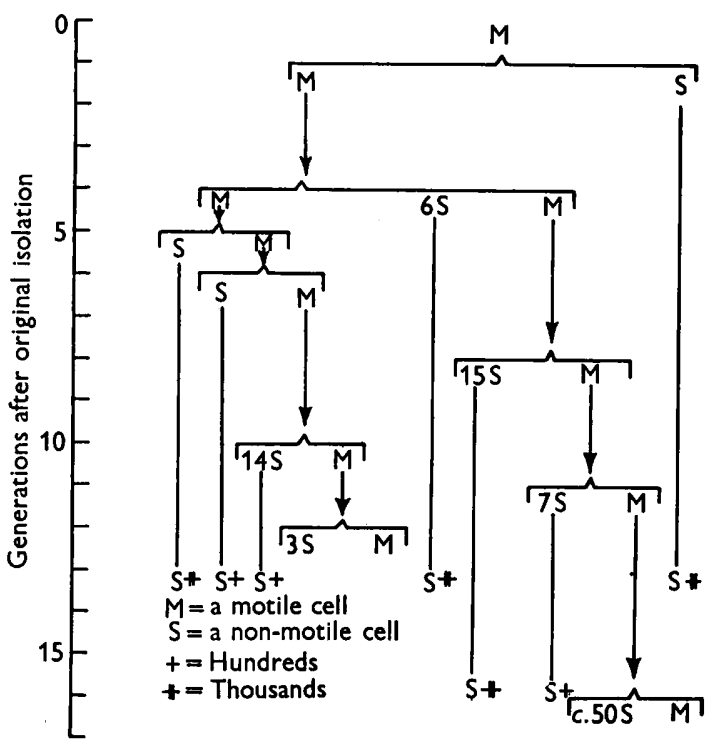

Fig. 1. Behaviour of the progeny of a motile bacterium isolated by micromanipulation from a culture of Salmonella typhimurium O strain SL 191/G. Micro-cultures were incubated at room temperature $\left(c .20^{\circ}\right)$ and examined at intervals; motile bacteria were re-isolated to separate droplets as indicated by arrows.

In this series of experiments about twenty motile bacteria were tested by repeated reisolation in this way. The shortest observed 'life' of an assumed MC particle was one generation, i.e. at the two-cell stage neither daughter of a motile bacterium was itself motile. The most persistent transmission of motility lasted $c .16$ generations; persistence for $c .5$ to 10 generations was typical. All the motile cells behaved in a manner consistent with the MC particle hypothesis. Additional evidence in favour of the hypothesis was provided by observations on the fission of bacteria inferred to have one $\mathrm{MC}$ particle. Such bacteria were occasionally observed at the moment of fission: one daughter remained motile whilst the other was non-motile from the instant of separation.

No motile bacteria were seen in about $30 \%$ of the micro-cultures described in Table 5. Assuming the hypothesis of MC particles, there are several possible explanations for this. Motile bacteria can become mechanically immobilized by sticking at an interface of the hanging drop and this was often 
observed; the particle-bearing cell might die, the particle itself might cease its activity, and the observer might miss a motile bacterium amongst many non-motile bacteria. The numbers of motile organisms recorded must be regarded as minimum estimates. Possible observer bias, e.g. in length of time devoted to examination of a particular micro-culture, was reduced by working concurrently with a number of unrelated micro-cultures-the course of experiments was reconstructed in 'pedigree' form only when work had ceased. If more than two motile bacteria had been present in the lineage illustrated (Fig. 1) they should have been detected at some stage during the experiment. The repeated detection of such motile bacteria over a number of generations of fission suggests that the efficiency of detection is high. The results in Table 5 bear on this point, for the micro-cultures in which no motile bacteria were detected arose ex hypothesi from bacteria with at least one MC particle. The proportion of such cultures can be regarded as an indication of the probability of failure, from all causes, to detect motile bacteria containing one MC particle during a single period of observation.

\section{DISCUSSION}

The presence of rare motile bacteria in a Salmonella typhimurium $\mathbf{O}$ strain, SL191/G, has thus been investigated in semi-solid medium and by micromanipulation. The evidence obtained from these two lines of work is complementary. The distribution of numbers of satellite micro-colonies (each presumed to arise from a motile bacterium) indicates that 'events' occur, each event giving rise to an average of about 2.5 micro-colonies. Presumably such events give rise to an average of this number of motile bacteria able to swim in the semi-solid medium. Micromanipulation experiments on single motile bacteria provides evidence which supports the hypothesis of MC particles. Taken together, these lines of evidence suggest that the events detected in semi-solid medium result from the synthesis of a small number of MC particles in a hitherto non-motile bacterium.

The suggestion that MC particles are synthesized in 'bursts' of small numbers, presumably as a result of some discontinuous biochemical process, will be referred to as the 'event hypothesis'. It is illustrated in Fig. 2 which represents the occurrence of an event in a non-motile bacterium. An arbitrary duration of less than one generation-time for the event is shown; during this period a small number of MC particles are synthesized. The particle-bearing bacteria become motile and in semi-solid media would initiate satellite microcolonies. The sharing-out of MC particles amongst the progeny of the cell in which they were synthesized is also illustrated in Fig. 2. Bacteria, inferred in retrospect to have had several $\mathbf{M C}$ particles, when isolated gave rise to small numbers of motile progeny during their first few divisions after isolation; thereafter no increase occurred in the numbers of their motile descendants (Stocker, 1956b); similar results were obtained in the present work. This implies that MC particles are shared between daughter cells so that eventually each motile bacterium will have only one particle and then no further increase 
will occur in numbers of motile progeny. If this is so, a bacterium which had several particles when isolated must have been closely related to, or identical with, a bacterium in which an event had occurred.

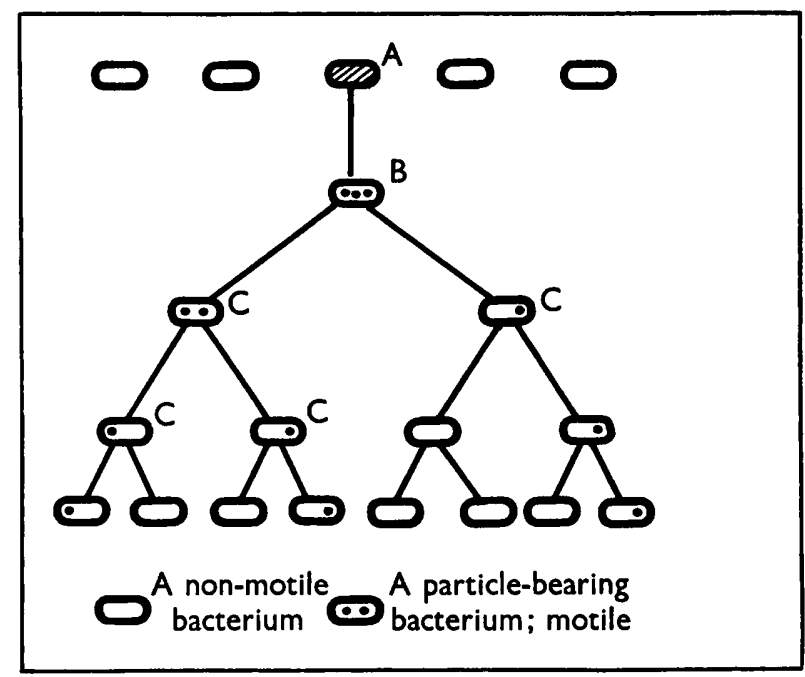

Fig. 2. The event hypothesis: the occurrence of an event (A) in a non-motile bacterium results in (B) the synthesis of a small number of MC particles which are shared-out (C) during growth and division.

The MC particle hypothesis has been fully discussed by Stocker $(1956 b)$ and by Lederberg (1956). The present work demonstrates that such particles occur spontaneously in the strain SL191/G: they have also been demonstrated by micromanipulation in rare, spontaneously occurring, motile bacteria isolated from two other Salmonella $O$ strains (Quadling, unpublished). Presumably MC particles also occur in all those non-motile strains which produce satellite micro-colonies in semi-solid medium. The evidence obtained in the present studies, though indirect, is consistent with the suggestion that one MC particle corresponds to one flagellum (or, in the case of paralysed strains, to one functioning flagellum). For example, one might expect a bacterium with several flagella (MC particles) to be more strongly motile than a bacterium with only one. If bacteria with one MC particle were able to swim in semisolid medium then an event occurring early in the growth of a parent colony would be expected to yield many more satellite micro-colonies than a similar event occurring later. That this is not so can be inferred from the fact that the average number of satellites produced per event does not change appreciably during growth of the parent colonies (Table 4). Presumably satellite microcolonies are initiated by bacteria with several MC particles-during growth and early divisions of such bacteria the number of MC particles per bacterium will be reduced to a critical value below which no swimming can occur in the semisolid medium. Stocker (1956b) also concluded, from experiments on the abortive transduction of motility, that bacteria with several MC particles were 
able to travel through a semi-solid medium whereas bacteria with only a single particle could not do so. In studies on Salmonella strains in which motile bacteria can occur at high frequency we have shown (Quadling, to be published; Quadling, 1956a, $b$ ) that there is a good correlation between the distributions of numbers of MC particles per bacterium, inferred by micromanipulation studies, and the distributions of numbers of stained flagella per bacterium. We have also shown (Quadling \& Stocker, 1956; Quadling, 1956a) that flagella are distributed about equally between daughter cells, as was predicted on the basis of the behaviour of MC particles.

The work reported here has shown that in each of a number of Salmonella $\mathbf{O}$ strains there is heterogeneity apropos of motility. Unless events are so rare as to be undetectable, or so frequent as to occur in all or nearly all individuals, it is clear that there will be detectable heterogeneity in a population. The precise mechanism of an event remains a matter for speculation. In formal, and doubtless oversimplified terms, an affected cell can be regarded as changing from a 'non-synthesizing' state, in which MC particles are not formed, to a transient 'synthesizing' state in which they are. The observations can be formally described in terms of an appropriate random mutation rate to the 'synthesizing' state coupled with a very high back-mutation rate to 'nonsynthesizing'. Delbrück (1945) has calculated that a gene mutation with a reversion rate of $\mathbf{0 . 5}$ or more per cell generation would be unable to persist to give a mutant clone; a similar back-mutation rate would be required to explain the impersistence of the 'synthesizing' state. It seems implausible to attribute the 'non-synthesizing' $\rightleftharpoons$ 'synthesizing' transition to gene mutation and almost instantaneous back-mutation; this would predicate a high degree of instability of the genetic material. Whilst such instability cannot be excluded it seems preferable, for economy of hypothesis, to regard these transitions as changes in phenotype only, whose precise cause remains unknown. In the strain studied events leading to satellite formation occur at a rate of about $10^{-5}$ per bacterium per generation-time; we infer that each bacterium has this probability of undergoing a transient change of phenotype to the flagella-synthesizing state. Such spontaneous transient changes of phenotype with respect to an all-or-none, or discontinuously variable, character may be termed 'phenotypic excursions'. An excursion perhaps results from some underlying continuously variable cell character temporarily passing beyond a threshold value. The postulated phenotypic excursions may perhaps be formally related to quasi-continuous variation in mice (Grüneberg, 1952). Grüneberg's studies on skeletal defects, which appeared in some animals but not others of pure-line strains of mice, led him to suggest that the underlying basis for the defects was a continuous variable associated with a physiological threshold. Possibly quasi-continuous variation results from a physiological 'phenotypic excursion' occurring at a critical stage in development.

The frequency of satellite-producing events, which we interpret as a measure of the probability of phenotypic excursion to the flagella-synthesizing condition, per bacterium per generation time, was approximately constant (in a standard environment) in the strain investigated; in other 
strains it has been shown to alter through mutation (Quadling, 1956a); we conclude that this frequency or probability is genetically determined. Stocker et al. (1953) found by transduction experiments that there were a number of genetic loci in Salmonella, mutation at any of which rendered the strain non-motile by preventing the synthesis of flagella; further experiments of the same sort (Quadling, 1956 $a$; Stocker \& Quadling, unpublished) showed that there are at least thirteen such loci, concerned with the synthesis of functional (i.e. non-paralysed) flagella. The non-motile strains tested in semisolid medium (Table 1) included thirteen strains, each non-motile through mutation at a different locus; eight of these strains produced satellites. It now appears that the effect of many mutant genes conferring 'non-motility' is to reduce the proportion of bacteria capable of synthesizing effective flagella to a very low level, but not to zero.

In strain SL 191/G the great majority of the population are non-motile and flagella cannot be detected in stained preparations, whilst a small minority of the population produce MC particles which we believe to be flagella; we infer that effective synthesis of flagella is confined to a small proportion of the population. This infrequent synthesis of flagella may be formally analogous to 'leakage' described in Neurospora spp. by Bonner, Yanofsky \& Partridge (1952). They showed that certain mutants which lacked the 'wild-type' ability to synthesize certain growth-factors were able to synthesize very small amounts of the required factor. This biochemical ability they attributed to 'leakage', implying that the genetic block in synthesis was not absolute. In the absence of a character, such as motility, which permits the detection of differences between individuals, the distribution of a given biochemical activity amongst a population remains unknown. Whilst the activity of a population must be the sum of the activities of its component individuals, the present work provides evidence that the activity of the individual is not necessarily the average activity for the population.

We wish to thank those who have provided us with non-motile cultures for use in these studies. Our thanks are due to Dr C. J. Perret and other colleagues and friends for much helpful discussion. It is also a pleasure to acknowledge the technical assistance of Mrs M. Worth. This paper is based on a Ph.D. thesis submitted by one of us (C.Q.) to the University of London, 1956.

\section{REFERENCES}

Asheshov, I. N. (1941). Papain digest media and standardisation of media in general. Canad. publ. Hlth J. 32, 468.

Bonner, D. M., Yanofsky, C. \& Partridge, C. W. H. (1952). Incomplete genetic blocks in biochemical mutants of Neurospora. Proc. nat. Acad. Sci., Wash., 38, 25.

Delbrück, M. (1945). Spontaneous mutations of bacteria. Ann. Mo. bot. Gdn, 32, 223.

Edwards, P. R. \& Bruner, D. W. (1942). Serological identification of Salmonella cultures. Circ. Ky agric. Exp. Sta. no. 54.

Fonbrune, P. DE (1949). Technique de micromanipulation. Paris: Masson. 
GRÜNEBERG, H. (1952). Genetical studies on the skeleton of the mouse. IV. Quasicontinuous variations. J. Genet. 51, 95.

Jordan, E. O., CaIdwell, M. E. \& Reiter, D. (1934). Bacterial motility. J. Bact. 27, 165.

LeDERBERG, J. (1956). Linear inheritance in transductional clones. Genetics, 41, 845.

Mrues, A. A. \& Mrsra, S. S. (1938). The estimation of the bactericidal power of the blood. J. Hyg., Camb. 38, 732.

Newcombe, H. B. (1948). Delayed phenotypic expression of spontaneous mutations in Escherichia coli. Genetics, 33, 447.

QuAding, C. (1956a). Genetic and environmental determination of bacterial motility, with special reference to Salmonella. Ph.D. thesis. University of London.

Quaduing, C. (1956b). In The Lister Institute of Preventive Medicine: Report of the Governing Body, 1956, p. 8.

Quadring, C. \& Stocker, B. A. D. (1956). An environmentally induced transition from the flagellated to the non-flagellated state in Salmonella: the fate of parental flagella at cell division (Abstract). J. gen. Microbiol. 15, i.

STocker, B. A. D. (1956a). Bacterial flagella; morphology, constitution and inheritance. In Bacterial Anatomy, Symp. Soc. gen. Microbiol. 6, 19.

STocker, B. A. D. (1956b). Abortive transduction of motility in Salmonella; a nonreplicated gene transmitted through many generations to a single descendant. J. gen. Microbiol. 15, 575.

Stocker, B. A. D., Zinder, N. D. \& Lederberg, J. (1953). Transduction of flagellar characters in Salmonella. J. gen. Microbiol. 9, 410.

\section{EXPLANATION OF PLATE}

Fig. 1. Appearance of Salmonella typhimurium O strain SL191/G on semi-solid medium after $18 \mathrm{hr}$. at $37^{\circ}$. Numerous satellite micro-colonies are associated with the streaks of bacterial growth present at the sites of inoculation. $\times 0 \cdot 9$.

Fig. 2. View of the edge of streak shown in Fig. $1 . \times 20$.

Fig. 3. 'Parent' colonies, some of which have associated satellites, from a pour-plate experiment with strain SL 191/G in semi-solid medium: $5 \mathrm{hr}$. at $37^{\circ}$, then $24 \mathrm{hr}$. at $20^{\circ}$. $\times 3$. 
Journal of General Microbiology, Vol. 17, No. 2

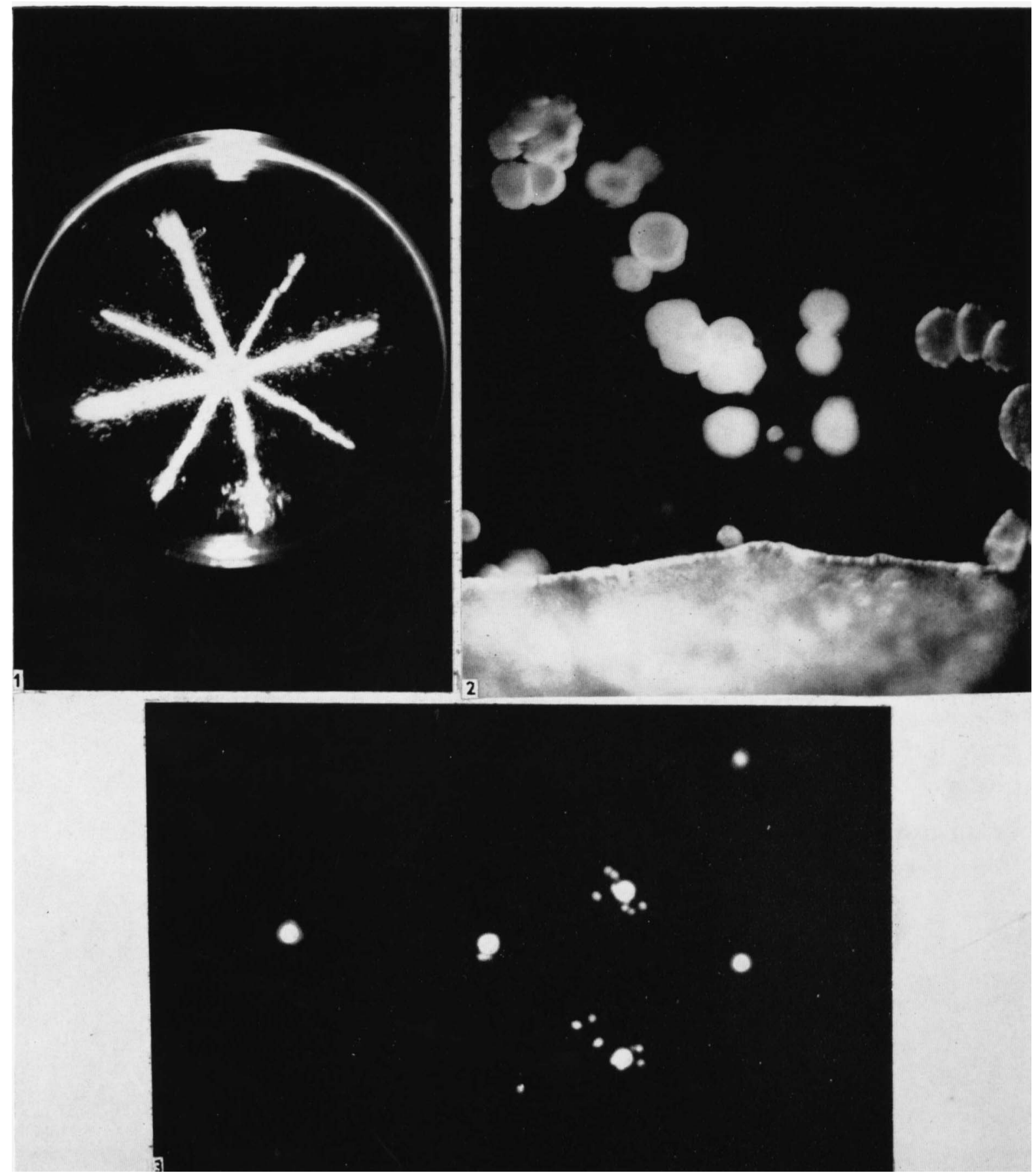

C. Quadling \& B. A. D. Stockier-Motile bacteria in Non-motile strains. Plate 1 